\title{
Critical appraisal of the use of alpha lipoic acid (thioctic acid) in the treatment of symptomatic diabetic polyneuropathy
}

This article was published in the following Dove Press journal:

Therapeutics and Clinical Risk Management

5 September 201 I

Number of times this article has been viewed

\section{Courtney E Mcllduff \\ Seward B Rutkove}

Department of Neurology, Beth Israel Deaconess Medical Center,

Boston, MA, USA
Correspondence: Seward B Rutkove Division of Neuromuscular Disease, Department of Neurology, Harvard Medical School, Beth Israel Deaconess Medical Center, 330 Brookline Avenue, TCC-8I0, Boston, MA 02215, USA

$\mathrm{Tel}+\mathrm{I} 6176678130$

Fax +I 6176673175

Email srutkove@bidmc.harvard.edu
Background: The most common of the neuropathies associated with diabetes mellitus, diabetic sensorimotor polyneuropathy (DSPN) is a syndrome of diffuse, length-dependent, symmetric nerve dysfunction. The condition is linked with substantial morbidity, frequent healthcare utilization, and compromised quality of life due to related discomfort. Correspondingly, antidepressants, anticonvulsants, and opioids are regularly prescribed with the goal of pain control. However, the agents rarely provide complete pain relief and fail to address progression of the disorder. Whereas strict blood glucose control can slow the onset and worsening of DSPN, near-normoglycemia is not easily attainable. Evidence implicating oxidative processes in the pathogenesis of DSPN offers one potentially important therapeutic avenue. Due to its properties as a potent antioxidant, alpha lipoic acid (ALA) could mitigate the development of DSPN and attenuate resultant symptoms and signs. Approved for treatment of DSPN in Germany, the agent is not more widely used due to uncertainty about its efficacy and reported adverse effects. Here we review the effectiveness and tolerability of ALA in the treatment of symptomatic DSPN.

Methods: The MEDLINE, EMBASE, and Cochrane Library databases were searched for English-language literature on the topic. Randomized, blinded studies comparing parenteral and oral ALA with placebo in the treatment of peripheral neuropathy in diabetic adults were selected. Analysis included studies with a level of evidence of at least $2 \mathrm{~b}$.

Results: The current appraisal summarizes data from 1160 participants in the ALADIN, SYDNEY, ORPIL, SYDNEY 2, and ALADIN III trials. In four of the studies, ALA provided significant improvement in manifestations of DSPN.

Conclusion: Treatment with ALA $600 \mathrm{mg}$ iv daily for 3 weeks represents a well-tolerated and effective therapy for DSPN. An oral dose of $600 \mathrm{mg}$ daily administered for up to 5 weeks could offer benefits in symptoms and signs of DSPN without significant side effects.

Keywords: alpha lipoic acid, antioxidant, diabetes mellitus, neuropathy, thioctic acid

\section{Introduction}

Diabetes mellitus (DM) is estimated to affect 439 million adults throughout the world by $2030 .{ }^{1}$ Complications of DM include a variety of neuropathies, which can be classified as focal or diffuse. ${ }^{2}$ Cranial mononeuropathies, diabetic amyotrophy, and focal appendicular neuropathies fall into the 'focal' category. 'Diffuse' neuropathies include chronic inflammatory demyelinating polyneuropathy and diabetic sensorimotor polyneuropathy (DSPN), the latter being a condition characterized by generalized, length-dependent, symmetric nerve dysfunction. ${ }^{2}$

Of the neuropathies associated with DM, DSPN is the most common. ${ }^{2,3}$ The prevalence increases from $10 \%$ within the first year of a DM diagnosis to $50 \%$ after 
25 years. ${ }^{4}$ Whereas the majority of cases are asymptomatic, symptomatic DSPN represents an important clinical challenge in type 1 and type 2 DM populations. ${ }^{3,5}$ Beyond substantial morbidity and mortality, painful DSPN translates into emotional distress, sleep disturbance, decreased productivity, and increased demands on healthcare resources. ${ }^{6-11}$

Given a reduced quality of life, it is not surprising that patients seek treatment for DSPN. ${ }^{7}$ Patients most commonly report hot, burning, electric, sharp, achy, and tingling sensations in a stocking-glove distribution. ${ }^{8}$ Many of these symptoms are attributable to small-fiber neuropathy, which often precedes large fiber dysfunction. ${ }^{2}$ Alternatively, patients may present with negative symptoms, such as numbness and gait unsteadiness, suggestive of large fiber damage. ${ }^{2}$

In the absence of alternative etiologies, length-dependent deficits in pinprick, temperature, light touch, proprioception, and vibration sense are objective markers of DSPN. ${ }^{2}$ Abnormalities in strength and reflexes can also occur in advanced stages of disease. ${ }^{2,3}$ The concomitants of nerve fiber injury can be detected on nerve conduction studies and electromyography. Reductions in distal sensory response amplitudes and conduction velocities are evident prior to the development of motor abnormalities, thereby paralleling the clinical course of DSPN. ${ }^{2}$

\section{Pathogenesis of DSPN}

Chronic hyperglycemia is believed to play a key role in the pathogenesis of DSPN via oxidative stress generated in heterogeneous and overlapping pathways. ${ }^{12-14}$ Enhanced flux through the polyol pathway, glucose auto-oxidation, and accumulation of advanced glycation end-products are thought to cause oxidative stress; in turn oxidative stress downregulates Na-K-ATPase activity and results in nerve ischemia. ${ }^{12,14}$ Endoneurial hypoxia and microvascular damage may also occur from the downstream inactivation of nitrous oxide and, thereby, increased vascular tension coupled with decreased blood flow. ${ }^{12}$ Oxidative stress resulting from hyperglycemia is also reported to cause programmed cell death. ${ }^{12,14}$ Increased sorbitol, decreased myo-inositol, protein kinase $\mathrm{C}$ activation, changes in cellular processing, and immune complex deposition may contribute to the development of DSPN. ${ }^{2,12,14}$

\section{Treatment approaches: symptomatic and pathogenic}

As adjuncts to antidiabetic agents targeting tight glycemic control, many treatments are prescribed with the goal of DSPN symptom relief. Evidence-based guidelines recommend the graded use of tricyclic antidepressants, serotonin-norepinephrine reuptake inhibitors, antiepileptic drugs, opioids, and mexiletine. ${ }^{15,16}$ Topical agents such as capsaicin and lidocaine are also suggested. ${ }^{15}$ The effectiveness of the existing approach is suboptimal; research shows that mono- and combination therapies almost never provide complete pain pelief. ${ }^{15}$

Until recently, glycemic control was the only treatment aimed at etiologic factors in DSPN. Indeed, strict glycemic control over 4-5 years can reduce, postpone, and possibly prevent the development of neurological deficits, nerve conduction abnormalities, and autonomic dysfunction. ${ }^{17,18}$ While an effective cornerstone of therapy, near-normoglycemia is not always possible to achieve or maintain. ${ }^{19,20}$ Given the role of oxidative processes in DSPN, antioxidants could offer additional therapeutic benefit. Among the emerging therapies, one of the most promising is alpha lipoic acid (ALA).

\section{Alpha lipoic acid (Thioctic acid)}

The only fat and water-soluble antioxidant, ${ }^{12} \mathrm{R}$-lipoic acid (1,2-dithiolane-3-pentanoic acid) was incidentally discovered by Snell et al in 1937 as a potato extract required for bacterial growth; ${ }^{21}$ the agent was later characterized by Reed and colleagues in 1951 (Figure 1). ${ }^{12,14,23,24}$ Ultimately revealed to function as a cofactor for mitochondrial enzymes, ALA is created endogenously by plants and animals. ${ }^{14}$ After uptake into cells and tissues, it is reduced to dihydrolipoic acid (DHLA). ${ }^{14}$ Both ALA and DHLA are potent antioxidants, with the latter regenerating other factors such as vitamins $\mathrm{C}$ and $\mathrm{E}$ in addition to raising glutathione intracellularly. ${ }^{14,25}$ Further, both ALA and DHLA function as free radical scavengers. ${ }^{14,22}$

ALA is proposed to mitigate the development of DSPN by addressing reactive oxygen and nitrogen species that are overproduced in the setting of DM. ${ }^{14}$ In neuroblastoma cell cultures, the agent has been associated with the sprouting of neurites. ${ }^{26}$ In addition to a regenerative capacity, ALA offers protection against nerve ischemia in rats. ${ }^{12}$ Experimental models have also shown that the administration of ALA can significantly reduce the expression of glial and neuronal markers, decrease lipid peroxidation, and help correct deficits in nerve blood flow, oxidative stress, and distal sensory and motor nerve conduction. ${ }^{13,27,28}$

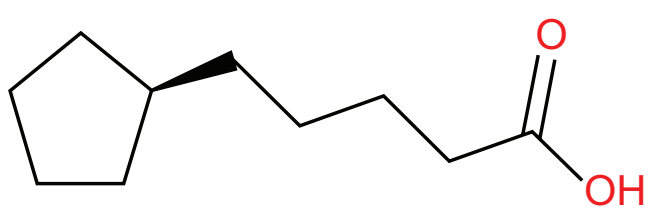

Figure I R-lipoic acid (I,2-dithiolane-3-pentanoic acid). 
Although synthesized de novo, ALA can also be absorbed from the diet. ${ }^{25,29,30}$ Dietary supplements ranging in doses from 200-600 mg are likely to provide up to 1000 times the amount of ALA available from a regular diet. ${ }^{30}$ Preclinical and clinical data indicate ALA is bioavailable and safe in moderate doses..$^{29}$ Gastrointestinal absorption is variable, and use with food decreases uptake. ${ }^{29,30}$ Accordingly, it is recommended that the agent be consumed 30 to 60 minutes before, or at least 120 minutes after, a meal. ${ }^{14,30}$ The antioxidant is very rapidly absorbed and cleared; maximum blood levels are achieved after 30 to 60 minutes, and the half-life of parenteral ALA is 30 minutes. ${ }^{30,31}$ It is thought to be extensively metabolized in the liver. ${ }^{14}$ Nevertheless, it is considered safe in hepatic and renal disease. ${ }^{22}$

Intravenous and oral forms of ALA are approved for the treatment of DSPN in Germany, where it is also covered by insurance. ${ }^{30,32}$ While not officially sanctioned in many countries, oral formulations are readily available over the counter and online. The agent is relatively inexpensive; in New Zealand currency, each $600 \mathrm{mg}$ tablet costs about 53 cents. ${ }^{33}$ Despite its qualities as a safe, available, inexpensive antioxidant, ALA is not widely used in part due to incomplete knowledge of its efficacy and adverse effects. The goal of this review is to assess the safety and effectiveness of treatment with parenteral and oral alpha lipoic acid on the symptoms, sensory deficits, and abnormal electrophysiological parameters of adults with symptomatic DSPN.

\section{Methods}

The MEDLINE, EMBASE, and Cochrane Library databases were searched for English-language literature on April 6 and April 11, 2011 using the terms 'lipoic acid', 'alpha lipoic acid', 'thioctic acid', 'trometamol salt of thioctic acid', 'diabetes', 'diabetic neuropathy', and 'painful peripheral neuropathy'. Randomized studies comparing the use of parenteral or oral ALA with placebo in the treatment of painful peripheral neuropathy in adults with type 1 and type 2 DM were selected. Meta-analyses and systematic reviews were also considered. Information on adverse events was culled from the trials. The reference lists of articles were also reviewed. Studies evaluating the effect of ALA on autonomic neuropathy and diabetic mononeuropathy were excluded. Studies for which primary data could not be obtained were excluded. As the one meta-analysis reviewed did not adhere to the standards of the Cochrane Collaboration, it was not included in the primary review. ${ }^{32}$

There was no disagreement among authors regarding the studies selected for inclusion.

\section{Results}

Five randomized double-blind placebo-controlled trials, the ALADIN, SYDNEY, ORPIL, SYDEY 2, and ALADIN III studies, comprising a total of 1160 people were selected (see Tables 1 and 2 for summaries of the studies). The study populations included individuals ranging in age from 18 to 74 years with type 1 and 2 DM. Mean body mass indices ranged from 27.7 to 30.9 . On average, initial glycosylated hemoglobin was $<12 \%$. The average duration of DM ranged from 10.4 to 15.1 years, while that of DSPN ranged from 2.8 to 5 years. The studies took place in inpatient and outpatient treatment centers throughout Germany, Russia, and Israel. The trials relied on mono- and multicenter participation. ${ }^{20,34-37}$

The five studies evaluated the effectiveness of ALA on DSPN using three different types of drug administration. Two studies evaluated the role of parental ALA compared with placebo. ${ }^{20,37}$ The parenteral treatment was given to separate intervention groups in doses of $100 \mathrm{mg}$ daily, $600 \mathrm{mg}$ daily, and $1200 \mathrm{mg}$ daily. A total of 14 treatments were given over 3 weeks in both studies. ${ }^{20,37}$ Two of the studies examined the effects of oral ALA relative to control patients with DSPN. ${ }^{34,35}$ Oral treatment was given to individual groups at total daily doses of $600 \mathrm{mg}, 1200 \mathrm{mg}$, and $1800 \mathrm{mg}$. Duration of treatment ranged from 3 to 5 weeks. ${ }^{34,35}$ One trial included a combination of parenteral and oral alpha lipoic acid given sequentially. ${ }^{36}$ Combination therapy included schedules of ALA $600 \mathrm{mg}$ iv daily for 3 weeks prior to $1800 \mathrm{mg}$ orally daily for 6 months and $600 \mathrm{mg}$ iv daily prior to oral placebo for 6 months versus iv placebo treatment followed by oral placebo treatment. The total study duration was 7 months. ${ }^{36}$

The trials included a variety of outcome measures including symptom scores, clinical signs, and electrophysiology. All 5 included trials used the subjective measure of Total Symptom Score (TSS) as the primary endpoint (Table 3). The TSS is the summation of the presence, severity, and duration of lancinating pain, burning pain, prickling, and numbness. Total scores can range from 0 to 14.64; a peak score suggests the continuous presence of severe discomfort in all four symptom domains. Beyond statistically significant changes in the measure, a clinically meaningful improvement in TSS was defined as a mean difference of at least 1.83 points. ${ }^{34,38}$ Several secondary measures of patient experience were also reported, including the four individual components of the TSS, the Number-Severity-Change (NSC) metric, the Global Assessment of Efficacy (GAE), and the Hamburg Pain Adjective List (HPAL). 
Table I Placebo-controlled trials studying the efficacy of parenteral and oral alpha lipoic acid in the treatment of symptoms, clinical signs, and electrophysiology of diabetic sensorimotor polyneuropathy

\begin{tabular}{|c|c|c|c|c|c|c|c|c|c|c|c|}
\hline \multirow[t]{2}{*}{ Trial } & \multirow[t]{2}{*}{$\mathbf{N}$} & \multirow[t]{2}{*}{$\begin{array}{l}\text { Trial } \\
\text { duration }\end{array}$} & \multirow[t]{2}{*}{ Route } & \multirow[t]{2}{*}{ Treatment arms } & \multicolumn{4}{|c|}{$\begin{array}{l}\text { Subjective measures of } \\
\text { improvement reaching } \\
\text { statistical significance } \\
\text { relative to placebo } \\
(P<0.05)\end{array}$} & \multicolumn{2}{|c|}{$\begin{array}{l}\text { Clinical measures } \\
\text { of improvement } \\
\text { reaching statistical } \\
\text { significance relative } \\
\text { to placebo }(P<0.05)\end{array}$} & \multirow{2}{*}{$\begin{array}{l}\text { Electrophysiological } \\
\text { measures of } \\
\text { improvement } \\
\text { reaching statistical } \\
\text { significance relative } \\
\text { to placebo } \\
(P<0.05) \\
\end{array}$} \\
\hline & & & & & TSS & NSC & GAE & HPAL & NIS & NDS & \\
\hline \multirow[t]{3}{*}{ ALADIN } & 326 & 3 weeks & iv & *ALA 100 mg daily & $x$ & NA & $x$ & $x$ & NA & $x$ & NA \\
\hline & & & & *ALA 600 mg daily & $\checkmark$ & & $\checkmark$ & $\checkmark$ & & $x$ & \\
\hline & & & & *ALA I200 mg daily & $\checkmark$ & & $x$ & $\checkmark$ & & $\checkmark$ & \\
\hline SYDNEY & 120 & 3 weeks $^{\mathrm{a}}$ & iv & *ALA 600 mg daily & $\checkmark$ & $\sqrt{b}$ & $\checkmark$ & NA & $\checkmark$ & NA & $\begin{array}{l}\checkmark \text { distal latency of } \\
\text { sural nerve }\end{array}$ \\
\hline ORPIL & 24 & 3 weeks & po & $\begin{array}{l}* \text { ALA } 600 \mathrm{mg} \text { three } \\
\text { times daily }\end{array}$ & $\checkmark$ & NA & NA & $x$ & NA & $\checkmark$ & NA \\
\hline \multirow[t]{3}{*}{ SYDNEY 2} & 181 & 5 weeks $^{\mathrm{a}}$ & po & *ALA 600 mg daily & $\checkmark$ & $\checkmark$ & $\checkmark$ & NA & $x$ & NA & Results not reported \\
\hline & & & & *ALA I 200 mg daily & $\checkmark$ & $\checkmark$ & $\checkmark$ & & $\checkmark$ & & \\
\hline & & & & *ALA I800 mg daily & $\checkmark$ & $\checkmark c$ & $\checkmark$ & & $x$ & & \\
\hline \multirow[t]{3}{*}{ ALADIN III } & 509 & $\begin{array}{l}3 \text { weeks/ } \\
6 \text { months }\end{array}$ & iv/po & $\begin{array}{l}\text { *ALA } 600 \text { mg daily/ } \\
\text { placebo }\end{array}$ & $x / x$ & NA & NA & NA & $\checkmark / x$ & NA & NA \\
\hline & & & & *ALA 600 mg daily/ & $x / x$ & & & & $\checkmark / x$ & & \\
\hline & & & & $\begin{array}{l}600 \mathrm{mg} \text { three times } \\
\text { daily }\end{array}$ & & & & & & & \\
\hline
\end{tabular}

Notes: N, number of participants initially enrolled; $\checkmark$, significance was achieved; $x$, significance was not achieved; afollowing a I-week placebo run-in phase; ${ }^{b}$ statistical significance was achieved for positive and negative sensory, but not motor and autonomic, symptoms; call metrics were significant except NSC number.

Abbreviations: TSS, Total Symptom Score; NSC, Number, Severity, Change; GAE, Global Assessment of Efficacy; HPAL, Hamburg Pain Adjective List; NIS, Neuropathy Impairment Score; NDS, Neuropathy Disability Score; iv, intravenous; po, oral; ALA, alpha lipoic acid; NA, not applicable.

In addition to measures of subjective improvement, studies also gauged the effect of ALA on measurable clinical signs. Two secondary measures comprised the Neuropathy Impairment Score (NIS) and the NIS in the lower limbs (NIS-LL). Endpoints also included the Neuropathy Disability Scale (NDS), a quantified neurological examination derived from cranial nerve, sensory, motor, and reflex integrity. ${ }^{39}$ Electrophysiological measures variably included amplitude, velocity, and latency of the tibial and peroneal nerves in addition to the amplitude and latency of the sural nerve.

\section{ALA efficacy: parenteral administration}

In the Alpha-Lipoic Acid in Diabetic Neuropathy (ALADIN) Trial, (level of evidence 1b), ${ }^{32} 328$ patients with DM 2 were recruited. Three hundred and twenty-six participants were randomized to one of four groups in a multicenter, double-blind, placebo controlled study. Eighty-two patients were given a placebo. Members of treatment groups received ALA at doses of $100 \mathrm{mg}$ per day $(\mathrm{n}=81), 600 \mathrm{mg}$ per day $(n=77)$, or $1200 \mathrm{mg}$ per day $(\mathrm{n}=86)$ by iv. The drug was administered on 14 days over the course of 3 weeks. A significant decrease in TSS was noted in the intervention group relative to placebo by day 5 ; the effect was maintained until treatment end. There was no significant difference between the mean changes in TSS scores for the $100 \mathrm{mg}$ per day treatment group and the placebo group. In addition to significant improvements from baseline TSS (5 points, $P<0.001$ in the $600 \mathrm{mg}$ group, 4.5 points, $P=0.003$ in the $1200 \mathrm{mg}$ group), there were significant improvements in the components of burning, paresthesias, and numbness in the $600 \mathrm{mg}$ and $1200 \mathrm{mg}$ groups $(P<0.05)$. The percentage of patients who experienced a clinically meaningful response reached significance in the $600 \mathrm{mg}$ per day group relative to placebo $(P=0.002)$. The HPAL showed commensurate reductions in pain with both treatment groups compared with placebo $(P<0.001)$. Physicians rated global efficacy of ALA as very good or good in a significantly greater proportion of patients in the $600 \mathrm{mg}$ per day treatment group relative to placebo $(P=0.001)$. A dose of $1200 \mathrm{mg}$ per day resulted in 
Table 2 Placebo-controlled trials studying the safety of parenteral and oral alpha lipoic acid in the treatment of symptomatic diabetic sensorimotor polyneuropathy

\begin{tabular}{|c|c|c|c|c|c|c|c|}
\hline Trial & $\mathbf{N}$ & $\begin{array}{l}\text { Trial } \\
\text { duration }\end{array}$ & Route & Study groups & $\begin{array}{l}\text { Percentages } \\
\text { of participants } \\
\text { reporting } \\
\text { adverse effects }\end{array}$ & $\begin{array}{l}\text { Adverse effects } \\
\text { reaching statistical } \\
\text { significance relative } \\
\text { to placebo }(P<0.05)\end{array}$ & $\begin{array}{l}\text { Types of adverse effects } \\
\text { reported }\end{array}$ \\
\hline \multirow[t]{4}{*}{ ALADIN } & 326 & 3 weeks & iv & *Placebo & $20.7 \%$ & & \\
\hline & & & & *ALA 100 mg daily & $13.6 \%$ & $x$ & Headache, nausea, vomiting \\
\hline & & & & *ALA 600 mg daily & $18.2 \%$ & $x$ & \\
\hline & & & & *ALA I 200 mg daily & $32.6 \%$ & $\checkmark$ & \\
\hline \multirow[t]{2}{*}{ SYDNEY } & 120 & 3 weeks & iv & *Placebo & $5.8 \%^{\mathrm{a}}$ & Not reported & Not specified ${ }^{c}$ \\
\hline & & & & *ALA 600 mg daily & $0.83 \%^{\mathrm{a}}$ & & \\
\hline \multirow[t]{2}{*}{ ORPIL } & 24 & 3 weeks & po & *Placebo & $4.17 \%^{\mathrm{a}}$ & Not reported & Myocardial infarction ${ }^{d}$ \\
\hline & & & & $\begin{array}{l}* \text { ALA } 600 \mathrm{mg} \text { three } \\
\text { times daily }\end{array}$ & None reported & & \\
\hline \multirow[t]{4}{*}{ SYDNEY 2} & 181 & 5 weeks & po & *Placebo & $21 \%$ & & \\
\hline & & & & *ALA 600 mg daily & $27 \%$ & $x$ & Nausea, vomiting, vertigo \\
\hline & & & & *ALA 1200 mg daily & $43 \%$ & $\checkmark$ & \\
\hline & & & & *ALA I 800 mg daily & $54 \%$ & $\checkmark$ & \\
\hline \multirow[t]{5}{*}{ ALADIN III } & 509 & 3 weeks/ & iv/po & *Placebo/placebo & $44.6 \%^{\mathrm{b}}$ & & \\
\hline & & 6 months & & *ALA 600 mg daily/ & $37.9 \%^{\mathrm{b}}$ & $x$ & Not specified \\
\hline & & & & placebo & & & \\
\hline & & & & *ALA 600 mg daily/ & $46.1 \%$ & $x$ & \\
\hline & & & & $600 \mathrm{mg}$ three times daily & & & \\
\hline
\end{tabular}

Notes: N, number of participants initially enrolled; $\checkmark$, significance was achieved; $x$, significance was not achieved; ${ }^{2}$ values calculated from data provided in paper; ${ }^{b}$ rates reflect adverse effects from oral phase; 'none of the adverse events were deemed related to the trial medication; ${ }^{d}$ the myocardial infarction was experienced by a member of the placebo group.

Abbreviations: iv, intravenous; po, oral; ALA, alpha lipoic acid.

significant change in the NDS $(P=0.03)$. Of the 326 initially enrolled, 260 participants completed the trial. Adverse events were reported in all groups but only reached significance in the $1200 \mathrm{mg}$ per day arm $(P<0.05)$, with side effects including headache, nausea, and vomiting. ${ }^{37}$

The Symptomatic Diabetic Neuropathy (SYDNEY) Trial (level of evidence 1b) ${ }^{32}$ was an inpatient, single-center, randomized, double-masked placebo-controlled trial including a total of 120 patients with type 1 and 2 DM. Sixty participants were randomized to receive $600 \mathrm{mg}$ of ALA and 60 were randomized to receive a placebo. There was a 1-week placebo run-in phase for both groups. The trial was conducted over the next 3 weeks, during which time 14 doses of ALA or placebo were given parenterally.

Table 3 Total Symptom Score measure for sticking or lancinating pain, burning, prickling, and numbness

\begin{tabular}{lllll}
\hline Symptom frequency & \multicolumn{4}{l}{ Symptom intensity } \\
\cline { 2 - 5 } & Absent & Slight & Moderate & Severe \\
\hline Occasional & 0 & $\mathrm{I}$ & 2 & 3 \\
Often & 0 & $\mathrm{I} .33$ & 2.33 & 3.33 \\
Continuous & 0 & 1.66 & 2.66 & 3.66 \\
\hline
\end{tabular}

Similar to the results of the ALADIN trial, a significant treatment effect was first appreciated in the experimental group relative to the placebo group by day 4; there was subsequent steady improvement thereafter. On the last day, the TSS of patients in the treatment group had improved by a mean of 5.72 points $(P<0.001)$. Further, there was significant improvement in all components (pain, burning, paresthesias, and numbness) measured by the TSS. Confirming the beneficial relationship between ALA and subjective relief, the SYDNEY Trial showed significant amelioration in the mean change of positive and negative sensory symptoms by the NSC metric $(P<0.05)$, although there was no significant improvement in perceptions of weakness. Patients rated the global efficacy of ALA as very good or good in a significantly greater proportion of participants in the $600 \mathrm{mg}$ per day treatment group relative to placebo $(P<0.01)$. Significant improvement in NIS scores $(2.7$ points, $P<0.001$ ) was also observed. The distal latency of the sural nerve was significantly shorter in the ALA group than in the placebo group $(P=0.017)$; however, no other significant effects on nerve conduction were identified. Of 120 participants, seven given placebo and one taking ALA 
reported unspecified adverse effects. None of the side effects were considered causally related to the experimental agent. One hundred eighteen participants completed the trial. ${ }^{20}$

\section{ALA efficacy: oral administration}

Twenty-four patients with DM 2 participated in the Oral Pilot (ORPIL) trial (level of evidence 1b), ${ }^{32}$ a singlecenter randomized, double-blind placebo-controlled study. Twelve patients were assigned to the placebo group. Twelve patients were assigned to a treatment group, in which ALA $600 \mathrm{mg}$ was administered orally three times daily. The trial demonstrated that a 3-week course of oral ALA at a dose of $1800 \mathrm{mg}$ a day translates into a significant reduction in the mean TSS for the feet ( 3.75 points, $P=0.021$ ). After 3 weeks, those in the treatment group also reported a significant improvement in the burning component of the TSS $(P=0.012)$. HPAL scores decreased but not to a level of significance. Relative to placebo, there was significant improvement in the NDS for the treatment group $(P=0.025)$. A total of 22 participants completed the trial. There were no differences in the adverse events between groups, and no specific side effects were reported. ${ }^{35}$

The findings were supported by the SYDNEY 2 trial (level of evidence 1b), ${ }^{32}$ a multicenter double-blind placebo-controlled study conducted over 5 weeks. In the study, 181 participants with DM 1 and 2 were randomized to receive a placebo $(n=43)$, ALA $600 \mathrm{mg}$ per day $(n=45)$, ALA $1200 \mathrm{mg}$ per day $(\mathrm{n}=47)$ or ALA $1800 \mathrm{mg}$ per day $(\mathrm{n}=46)$. Treatment was started after a 1-week placebo run-in phase. Significant improvements in TSS were noted by week 1 in the $1800 \mathrm{mg}$ group and by week 2 in the 600 and $1200 \mathrm{mg}$ groups. The significant improvements in total TSS were maintained at treatment end with all active doses $(P<0.05)$. Consistent with the ORPIL trial, the agent most effectively alleviated symptoms of pain and burning. Significant improvements were seen in NSC scores for all ALA doses relative to placebo $(P<0.05$ except NSC number in ALA 1800, $P=0.08)$. Members of all ALA groups rated treatment significantly more favorably than those in the placebo group $(P<0.05)$. Interestingly, significant improvement in the overall NIS was noted only at a dose of $1200 \mathrm{mg}(P<0.05)$, while sensory function in the lower limbs (NIS-LL) improved significantly with ALA $600 \mathrm{mg}$ per day over 5 weeks $(P<0.05)$. The results of nerve conduction studies were not reported. Of the initial 181 participants, 166 completed the trial. Fifteen left the study, mostly due to adverse effects including nausea, vomiting, and vertigo. Overall, side effects were reported by $27 \%$ of the $600 \mathrm{mg}$ group $(P=0.53), 43 \%$ of the $1200 \mathrm{mg}$ group $(P=0.03)$, and $54 \%$ of those in the $1800 \mathrm{mg}$ group $(P<0.001$ relative to placebo $) .{ }^{34}$

\section{ALA efficacy: sequential parenteral and oral administration}

Of the 509 participants initially enrolled, 383 completed the multicenter ALADIN III trial (level of evidence $2 b$ ). ${ }^{32}$ Conducted over a total of 7 months, DM 2 patients were randomized to one of three groups; the first group received placebo in a 3-week iv phase and the subsequent 6-month oral phase $(n=168)$. The second group received ALA $600 \mathrm{mg}$ iv daily for 3 weeks prior to oral placebo for 6 months $(n=174)$. The third group received ALA $600 \mathrm{mg}$ iv daily for 3 weeks followed by ALA $600 \mathrm{mg}$ three times daily for 6 months $(n=167)$. In contrast to the ALADIN and SYDNEY results, treatment with ALA $600 \mathrm{mg}$ iv daily in the ALADIN III trial was not associated with significant changes in mean TSS-feet when compared with placebo at 3 weeks. After an additional 6 months of $1800 \mathrm{mg}$ per day oral therapy, the area under the curve was smaller in the active groups. However, there was no significant difference in symptoms as rated by the TSS after 7 months between any of the active or control groups. The ALADIN III trial demonstrated improvement in NIS after the iv phase of treatment with ALA $600 \mathrm{mg}$ per day over 3 weeks. However, there was no significant difference in NIS after an additional 6 months of oral treatment at a dose of $600 \mathrm{mg}$ three times daily relative to placebo. The rates of side effects were not significantly different between groups. ${ }^{36}$

\section{Summary of data and discussion}

The current appraisal includes data derived from a total of 1160 participants enrolled in the ALADIN, SYDNEY, ORPIL, SYDNEY 2, and ALADIN III studies. Two trials comprising 446 patients in total explored the efficacy and safety of shortterm parenteral ALA treatment versus placebo. Compared with placebo, iv ALA was associated with significant, clinically meaningful improvements in sensory symptoms and neuropathic deficits. Doses of $600 \mathrm{mg}$ daily and $1200 \mathrm{mg}$ daily offered equivalent benefits, but the higher dose was associated with significantly more side effects than placebo. The results were confirmed in a meta-analysis pooling data from a total of 1258 participants in the ALADIN, ALADIN III, SYDNEY, and NATHAN II trials. ${ }^{40}$ While the validity of the research has been challenged, ${ }^{32,38}$ the work indicated that ALA $600 \mathrm{mg}$ iv daily for 3 weeks translates into a clear therapeutic benefit without significant side effects. ${ }^{40}$

Two trials consisting of 205 patients total evaluated the effectiveness and tolerability of short-term oral ALA 
treatment with placebo. Relative to placebo, oral ALA alleviated symptoms and impairments to a significant and clinically meaningful degree at total daily doses of $600 \mathrm{mg}$, $1200 \mathrm{mg}$, and $1800 \mathrm{mg}$. However, there was evidence of doserelated toxicity, with adverse event rates reaching significance at a dose of $1200 \mathrm{mg}$ and climbing at a dose of $1800 \mathrm{mg}$ daily after 5 weeks. The combination of parenteral (600 mg daily for 3 weeks) and oral therapy (600 mg three times daily for 6 months) administered over a total of 7 months failed to translate into significant improvements.

Studies exploring the efficacy of parenteral and oral ALA on the symptoms, signs, and electrophysiological parameters of DSPN date back to at least $1959 .{ }^{41}$ Validity of data from initial trials is constrained by small sample size, lack of blinding, absence of placebo control, and potentially inadequate treatment doses. ${ }^{38}$ While the quality of investigations has improved over time, even the most recent randomized double-blind placebo-controlled trials have some methodological limitations. ${ }^{38,42}$ Further, none provides true Class I evidence.

Although investigators of the reviewed trials may have calculated the number participants necessary to detect meaningful change in study endpoints, ultimate sample size was sometimes inadequate due to participant attrition; drop-out rate reached $25 \%$ in one of the studies included in the present analysis. ${ }^{36}$ Further, the incorporation of as many as 71 treatment sites in multicenter designs likely introduced variability in scoring that affected outcomes. ${ }^{36}$ Patients with DM 1 and DM 2 were included in the studies reviewed here. While DSPN represents an important clinical problem in both populations, the pathophysiology and response to treatment could differ. Similarly, the magnitude of therapeutic effect could be contingent on baseline status, and initial TSS varied widely across studies. While patients with a baseline TSS of at least 2 were included in one study, ${ }^{37}$ other trials required TSS be at least 7.5. ${ }^{20,34}$ Concurrent administration of certain diabetic therapies and antioxidants with ALA could also have influenced results. In three of the studies reviewed, use of diet, oral antidiabetics, and/or insulin constituted a criterion for inclusion. ${ }^{35-37}$ Although details of the therapies were not outlined, the authors noted the continuation of usual diabetic treatment throughout the study period in one instance..$^{20}$ Importantly, not all of the trials specifically excluded patients who were using, or had recently used, other antioxidants. ${ }^{20}$

Whereas the randomized controlled trials reviewed demonstrate significant improvement in symptoms and signs of neuropathy, there is little evidence that ALA has a meaningful effect on nerve conduction. One potential explanation is that ALA preferentially treats small fiber neuropathy, which is not measurable by electrodiagnostic studies. Alternatively, objective improvements in some clinical signs and nerve conduction could take years to manifest. Preliminary support for this notion is provided by two long-term studies. Despite methodological flaws, the ALADIN II trial demonstrated that treatment with ALA at doses of $600 \mathrm{mg}$ and $1200 \mathrm{mg}$ given parenterally for 5 days and then orally for 2 years led to significant improvements in nerve conduction. ${ }^{30}$ The international NATHAN I trial showed that neuropathy progressed in placebo conditions but improved with oral ALA $600 \mathrm{mg}$ daily over 4 years. ${ }^{43}$ Future trials evaluating long-term administration of ALA could better define the patterns of effectiveness and tolerability of the agent over years.

All of the reviewed studies suggest ALA is safe at a once daily dose of $600 \mathrm{mg}$ in both iv and oral forms. The investigations also demonstrate significant toxicity emerges at a dose of $1200 \mathrm{mg}$ once daily with both routes of administration after 3-5 weeks of treatment. ${ }^{34,37}$ Interestingly, ALA at a total daily dose of $1800 \mathrm{mg}$ was well tolerated when administered in three divided doses for as long as 6 months $^{35,36}$ but not as a single daily dose over just 5 weeks. ${ }^{34}$ The trend raises the possibility that higher amounts of ALA could be well-tolerated if given in smaller divided doses. Of note, the drug formulations varied across the studies and could have influenced side effect rates and symptom relief in meaningful ways.

The current body of evidence suggests that both parenteral and oral forms of ALA can translate into statistically significant symptom relief within 1 week, with steady and continuous improvement thereafter. ${ }^{20,34,37}$ However, it is uncertain if the trajectory of improvement continues, plateaus, or declines with prolonged treatment and following discontinuation of the agent. Some data indicate the benefits of ALA are not sustained following therapy completion. One study showed that after the discontinuation of ALA $600 \mathrm{mg}$ daily for a mean of 5 years, about $73 \%$ of patients developed neuropathic symptoms within 2 weeks in the absence of gabapentin therapy. ${ }^{44}$ Authors maintain that transitioning from ALA to gabapentin and other conventional medications resulted in increased side effects, more outpatient visits, and heightened daily cost of therapy. ${ }^{44}$ While the return of symptoms could represent the natural course of disease, it is unclear if transient use of ALA could ultimately worsen symptoms.

In the absence of symptoms, patients with DSPN do not necessarily seek evaluation. As experimental models suggest 
it has protective properties, starting ALA treatment at the time of DM diagnosis might improve its long-term benefits. Early initiation might be especially important because the ability to endogenously synthesize ALA declines with age in DM. ${ }^{30}$ In addition to optimal timing and duration of ALA therapy, future studies should explore the use of ALA in combination with other antioxidants given the multifaceted nature of oxidative stress in DSPN.

While there is some evidence that other antioxidants, such as vitamin E, can significantly ameliorate neuropathic symptoms and nerve conduction in patients with DM 2, ${ }^{45,46}$ larger scale trials generally fail to show significant improvements in hyperglycemia and diabetic complications. ${ }^{47,48}$ ALA could represent a superior treatment because it has unique properties as an antioxidant and insulin mimetic. ${ }^{14,22,30}$ Unlike other antioxidants, ALA is amphiphilic, allowing action in aqueous and lipid media. ${ }^{30}$ Thus, the positive effects of ALA on DSPN could reflect enhancement of its known role as a cofactor in mitochondrial reactions, but also in other systemic processes. Through downstream scavenging by DHLA and antioxidant recycling, ALA could initiate a cascade of events that continues to provide benefits long after its metabolism. ${ }^{14,22,30}$ Beyond its role as an antioxidant, ALA could also help mitigate complications of DM by improving insulin sensitivity and glucose disposal. ${ }^{14,22,30}$ Future studies should investigate optimal combinations of antidiabetic therapies and ALA.

\section{Conclusion}

Treatment with ALA $600 \mathrm{mg}$ iv daily for 3 weeks represents a well-tolerated and effective therapy for DSPN. Similarly, an oral dose of $600 \mathrm{mg}$ daily administered for up to 5 weeks could offer benefits in symptoms and signs of DSPN without significant side effects. Whereas a single study using sequential parenteral and oral therapy failed to show a significant effect, the preponderance of evidence supports the use of ALA in treating the symptoms and signs of DSPN. Further randomized, double-blind, placebo-controlled trials of larger scale and longer duration are necessary to strengthen existing data and provide greater insight into the long-term efficacy of ALA.

\section{Disclosure}

The authors report no conflicts of interest in this work.

\section{References}

1. Shaw JE, Sicree RA, Zimmet PZ. Global estimates of the prevalence of diabetes for 2010 and 2030. Diabetes Res Clin Pract. 2010;87: 4-14.

2. Rutkove SB. A 52-year-old woman with disabling peripheral neuropathy: review of diabetic polyneuropathy. JAMA. 2009;302: 1451-1458.
3. Tracey JA, Dyck JB. The spectrum of diabetic neuropathies. Phys Med Rehabil Clin N Am. 2008:19.

4. Sugimoto K, Murakawa Y, Sima AF. Diabetic neuropathy - a continuing enigma. Diabetes Metab Res Rev. 2000;16:408-433.

5. Dyck PJ, Kratz KM, Karnes JL, et al. The prevalence by staged severity of various types of diabetic neuropathy, retinopathy, and nephropathy in a population-based cohort: the Rochester Diabetic Neuropathy Study. Neurology. 1993;43:817-824.

6. Gore M, Brandenburg N, Dukes E, et al. Pain severity in diabetic peripheral neuropathy is associated with patient functioning, symptom levels of anxiety and depression, and sleep. J Pain Symp Manage. 2005; 30:374-385.

7. Gore M, Brandenburg NA, Hoffman DL, et al. Burden of illness in painful diabetic peripheral neuropathy: the patients' perspectives. J Pain. 2006;7:892-900.

8. Galer BS, Gianas A, Jensen MP. Painful diabetic polyneuropathy: epidemiology, pain description, and quality of life. Diabetes Res Clin Pract. 2000;47:123-128.

9. McDermott AM, Toelle TR, Rowbotham DJ, et al. The burden of neuropathic pain: results from a cross-sectional survey. Eur J Pain. 2006;10:127-135.

10. Abbott CA, Vileikyte L, Williamson S, et al. Multicenter study of the incidence of and predictive risk factors for diabetic neuropathic foot ulceration. Diabetes Care. 1998;21:1071-1075.

11. Coppini DV, Botwell PA, Weng C, et al. Showing neuropathy is related to increased mortality in diabetic patients - a survival analysis using an accelerated failure time model. J Clin Epidemiol. 2000;53: 519-523.

12. Vallianou N, Evangelopoulos A, Koutalas P. Alpha-lipoic acid and diabetic neuropathy. Rev Diabet Stud. 2009;6:230-236.

13. Baydas G, Donder E, Kiliboz M, et al. Neuroprotection by alpha-lipoic acid in streptozotocin-induced diabetes. Biochemistry (Mosc). 2004;69: 1001-1005.

14. Packer L, Kraemer K, Rimbach G. Molecular aspects of lipoic acid in the prevention of diabetes complications. Nutrition. 2001;17:888-895.

15. Argoff CE, Backonja M-M, Belgrade M, et al. Consensus Guidelines: treatment planning and options. Mayo Clin Proc. 2006;81 (4 Suppl):S12-S25.

16. Kuritzky L. Managing diabetic peripheral neuropathic pain in primary care. J Fam Pract. 2010;59(5 Suppl):S15-S22.

17. The Diabetes Control and Complications Trial Research Group. The effect of intensive diabetes therapy on the development and progression of neuropathy. Ann Intern Med. 1995;122:561-568.

18. Amthor K-F, Dahl-Jorgensen K, Berg TJ, et al. The effect of 8 years of strict glycaemic control on peripheral nerve function in IDDM patients: the Oslo Study. Diabetologica. 1994;37:579-584.

19. Ziegler D. Painful diabetic neuropathy: treatment and future aspects. Diabetes Metab Res Rev. 2008;24(Suppl 1):S52-S57.

20. Ametov AS, Barinov A, Dyck PJ, et al. The sensory symptoms of diabetic polyneuropathy are improved with alpha-lipoic acid: the SYDNEY trial. Diabetes Care. 2003;26:770-776.

21. Snell EE, Strong FM, Peterson WH. Growth factors for bacteria: Fractionation and properties of an accessory factor for lactic acid bacteria. Biochem J. 1937;31:1789-1799.

22. Poh ZX, Goh KP. A current update on the use of alpha lipoic acid in the management of type 2 diabetes mellitus. Endocr Metab Immune Disord Drug Targets. 2009;9:392-398.

23. Reed LJ, DeBusk BG, Gunsalus IC, Hornberger CS Jr. Crystalline alpha lipoic acid; acetalytic agent associated with pyruvate dehydrogenase. Science. 1951;114:93-94.

24. Reed LJ. The chemistry and function of lipoic acid. Adv Enzymol Relat Subj Biochem. 1957;18:319-347.

25. Packer L, Tritschler HJ, Wessel K. Neuroprotection by the metabolic antioxidant alpha-lipoic acid. Free Radic Biol Med. 1997;22: 359-378.

26. Dimpfel W, Spuler M, Pierau FK, et al. Thioctic acid induces dosedependent sprouting of neurites in cultured rat neuroblastoma cells. Dev Pharmacol Ther. 1990;14:193-199. 
27. Nickander KK, McPhee BR, Low PA, et al. Alpha-lipoic acid: antioxidant potency against lipid peroxidation of neural tissues in vitro and implications for diabetic neuropathy. Free Radic Biol Med. 1996;21: 631-639.

28. Nagamatsu M, Nickander KK, Schmelzer JD, et al. Lipoic acid improves nerve blood flow, reduces oxidative stress, and improves distal nerve conduction in experimental diabetic neuropathy. Diabetes Care. 1995; 18:1160-1167.

29. Shay KP, Moreau RF, Smith EJ, et al. Alpha-lipoic acid as a dietary supplement: molecular mechanisms and therapeutic potential. Biochim Biophys Acta. 2009;1790:1149-1160.

30. Singh U, Jialal I. Alpha-lipoic acid supplementation and diabetes. Nutr Rev. 2008;66:646-657.

31. Breithaupt-Grogler K, Niebch G, Schneider E, et al. Dose-proportionality of oral thioctic acid-coincidence of assessments via pooled plasma and individual data. Eur J Pharm Sci. 1999;8:57-65.

32. Mijnhout GS, Alkhalaf A, Kleefstra N, et al. Alpha lipoic acid: a new treatment for neuropathic pain in patients with diabetes? Neth $\mathrm{J} \mathrm{Med}$. 2010;68:158-162.

33. Ltd. PM. PriceMe-Online Shopping and Price Comparison New Zealand. 2011. http://www.priceme.co.nz/search.aspx?q=alpha+lipoic+acid. Accessed April 24, 2011.

34. Ziegler D, Ametov A, Barinov A, et al. Oral treatment with alpha-lipoic acid improves symptomatic diabetic polyneuropathy: the SYDNEY 2 trial. Diabetes Care. 2006;29:2365-2370.

35. Ruhnau KJ, Meissner HP, Finn JR, et al. Effects of 3-week oral treatment with the antioxidant thioctic acid (alpha-lipoic acid) in symptomatic diabetic polyneuropathy. Diabet Med. 1999;16:1040-1043.

36. Ziegler D, Hanefeld M, Ruhnau KJ, et al. Treatment of symptomatic diabetic polyneuropathy with the antioxidant alpha-lipoic acid: a 7-month multicenter randomized controlled trial (ALADIN III Study). ALADIN III Study Group. Alpha-Lipoic Acid in Diabetic Neuropathy. Diabetes Care. 1999;22:1296-1301.

37. Ziegler D, Hanefeld M, Ruhnau KJ, et al. Treatment of symptomatic diabetic peripheral neuropathy with the anti-oxidant alpha-lipoic acid. A 3-week multicentre randomized controlled trial (ALADIN Study). Diabetologia. 1995;38:1425-1433.
38. Tang J, Wingerchuk DM, Crum BA, et al. Alpha-lipoic acid may improve symptomatic diabetic polyneuropathy. Neurologist. 2007;13: 164-167.

39. Dyck PJ. Detection, characterization, and staging of polyneuropathy: assessed in diabetics. Muscle Nerve. 1988;11:21-32.

40. Ziegler D, Nowak H, Kemlpler P, et al. Treatment of symptomatic diabetic polyneuropathy with the antioxidant alpha-lipoic acid: a metaanalysis. Diabetes. 2004;21:114-121.

41. Biewenga G, Haenen GR, Bast A. The role of lipoic acid in the treatment of diabetic polyneuropathy. Drug Metab Rev. 1997;29:1025-1054.

42. Reljanovic M, Reichel G, Rett K, et al. Treatment of diabetic polyneuropathy with the antioxidant thioctic acid (alpha-lipoic acid): a two year multicenter randomized double-blind placebo-controlled trial (ALADIN II). Alpha Lipoic Acid in Diabetic Neuropathy. Free Radic Res. 1999;31:171-179.

43. Ziegler D. Painful diabetic neuropathy: advantage of novel drugs over old drugs? Diabetes Care. 2009;32(Suppl 2):S414-S419.

44. Ruessmann HJ. Switching from pathogenetic treatment with alpha-lipoic acid to gabapentin and other analgesics in painful diabetic neuropathy: a real-world study in outpatients. J Diabetes Complications. 2009;23: 174-177.

45. Farvid MS, Homayouni F, Amiri Z, et al. Improving neuropathy scores in type 2 diabetic patients using micronutrients supplementation. Diabetes Res Clin Pract. 2011. [Epub ahead of print].

46. Tutuncu NB, Bayraktar M, Varli K. Reversal of defective nerve conduction with vitamin $\mathrm{E}$ supplementation in type 2 diabetes: a preliminary study. Diabetes Care. 1998;21:1915-1918.

47. Suksomboon N, Poolsup N, Sinprasert S. Effects of vitamin E supplementation on glycaemic control in type 2 diabetes: systematic review of randomized controlled trials. J Clin Pharm Ther. 2011;36: 53-63.

48. Scott J, King G. Oxidative stress and antioxidant treatment in diabetes. Ann N York Acad Sci. 2004;1031:204-213.
Therapeutics and Clinical Risk Management

\section{Publish your work in this journal}

Therapeutics and Clinical Risk Management is an international, peerreviewed journal of clinical therapeutics and risk management, focusing on concise rapid reporting of clinical studies in all therapeutic areas, outcomes, safety, and programs for the effective, safe, and sustained use of medicines. This journal is indexed on PubMed Central, CAS,

\section{Dovepress}

EMBase, Scopus and the Elsevier Bibliographic databases. The manuscript management system is completely online and includes a very quick and fair peer-review system, which is all easy to use. Visit http://www.dovepress.com/testimonials.php to read real quotes from published authors. 